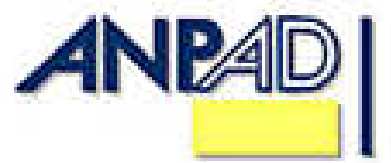

Disponível em

http://www.anpad.org.br/rac

RAC, Curitiba, v. 15 , n. 6 ,

pp. 1137-1151, Nov./Dez. 2011

(cc) 1 r

Documentos e Debates:

\title{
Estágio Docência: um Estudo no Programa de Pós-Graduação em Administração da Universidade Federal de Lavras ${ }^{(1)}$
}

\section{Apprenticeship Teaching: a Studying in the Post Graduation Programs of the Federal University of Lavras}

\author{
Nathália de Fátima Joaquim * \\ E-mail: nathaliafjoaquim@ hotmail.com \\ Universidade Federal de Minas Gerais - CEPEAD/UFMG \\ Belo Horizonte, MG, Brasil. \\ João Paulo de Brito Nascimento \\ E-mail: joaopaulo_de_brito@yahoo.com.br \\ Universidade Federal de Lavras - UFLA \\ Lavras, MG, Brasil.
}

Ana Alice Vilas Boas E-mail: ana.alice@dae.ufla.br Universidade Federal de Lavras - UFLA Lavras, MG, Brasil.

Fernanda Tavares Silva E-mail: fefetasilva@yahoo.com.br Universidade Federal de Lavras - UFLA Lavras, MG, Brasil.

\footnotetext{
* Endereço: Nathália de Fátima Joaquim Rua do Ferro, 323, Niterói, Divinópolis/MG, 35500-229.
}

Copyright (C) 2011 RAC. Todos os direitos, até mesmo de tradução, são reservados. É permitido citar parte de artigos sem autorização prévia, desde que seja identificada a fonte. 


\section{Introdução}

Nos últimos anos, verifica-se novo movimento de expansão de vagas nos cursos de graduação das universidades públicas brasileiras. Esta nova configuração procura responder a vários tipos de pressões, entre as quais se destaca o próprio crescimento do ensino público de nível médio, tecnológico e superior, pautadas pelas políticas públicas propostas pelo Estado. Embora seja movimento de proporções limitadas, ele é suficiente para que a questão da reposição e formação do corpo docente das universidades seja objeto de discussão.

De maneira geral, observa-se que, nos cursos de pós-graduação stricto sensu, o enfoque principal está na formação para a pesquisa científica, direcionando menor atenção ao preparo para a docência. Trata-se de questão basilar, uma vez que a importância da capacitação de mestres e doutores tem relação diretamente proporcional ao nível de qualificação da formação de profissionais da sua área. Diante da realidade dos programas de pós-graduação, nos quais os alunos são muito mais direcionados para a pesquisa do que para o ensino, o estágio docência seria boa alternativa metodológica eficaz para a formação de professores universitários?

Deste modo, este trabalho tem como objetivo relacionar as vantagens e desvantagens advindas da prática e contato direto com as atividades em sala de aula, por meio do estágio docência do Programa de Pós-graduação em Administração da Universidade Federal de Lavras (PPGA/UFLA). E, ainda, verificar a importância do estágio como ferramenta metodológica que pode aproximar ensino e pesquisa no ambiente acadêmico.

Os estudantes do PPGA/UFLA que participaram da disciplina Estágio Docência, no segundo semestre de 2008 e primeiro semestre de 2009, produziram, no final de suas atividades, relatórios com as principais considerações que cada um julgou relevantes com referência ao estágio. Por meio de análise documental desses relatórios é que se embasou o presente trabalho, uma vez que os pósgraduandos do PPGA/UFLA foram questionados acerca da atividade docente por eles praticada e, consequentemente, sobre suas percepções a respeito de variáveis que afetaram o processo do estágio, quanto a benefícios auferidos e dificuldades encontradas. Cabe ressaltar, ainda, que não é pretensão deste estudo esgotar a discussão e também não é do interesse do trabalho produzir um texto conclusivo sobre a reconciliação da teoria com a prática do ensino, mas apresentar abordagem alternativa de prática e análise da realidade do ensino no nível superior.

\section{Os Cursos de Pós-Graduação Stricto Sensu e as Atividades de Ensino e Pesquisa}

Segundo Chamlian (2003), os cursos de pós-graduação foram constituídos com o objetivo de formar professores competentes para atender à expansão do ensino superior, além de contribuir para a elevação dos níveis de qualidade do ensino oferecido. Outro fator importante é que esta é a principal fonte de formação do professorado do ensino superior e, também, do estímulo ao desenvolvimento da pesquisa científica. Porém, por meio de medidas concretas, os diversos planos nacionais de pósgraduação acentuaram, cada vez mais, a pesquisa como foco de tais programas. Todavia estes cursos não deixaram de ser, mesmo que de forma secundária, o meio mais efetivo de formação do professor universitário. No intuito de manter os níveis de qualidade do ensino ofertado pelas instituições, o governo federal passou a recomendar, como ferramenta de apoio, a criação da disciplina Metodologia do Ensino Superior como disciplina pedagógica, da pós-graduação.

Tendo em vista a possibilidade de atuação na atividade docente, a Coordenação de Aperfeiçoamento do Pessoal de Nível Superior (CAPES), em 1999, tornou obrigatória a participação em estágio supervisionado, como parte das atividades de bolsistas, alunos de mestrado e doutorado, sob sua tutela. Tal medida foi tomada para tentar minimizar o impacto causado no ensino superior, pelo fato de alunos dos cursos de pós-graduação poderem lecionar, mesmo que não tenham formação 
de caráter pedagógico. Isto refletiu a preocupação da instituição com a qualidade da formação de mestres e doutores na prática do ensino e não somente em pesquisa. No entanto Chamlian (2003, p. 59) afirma que "mais do que uma formação pedagógica, em sentido estrito, a necessidade está no despertar da valorização da tarefa de ensino". Para a autora, uma disciplina voltada para a formação pedagógica estrita, dificilmente daria conta de preencher a variedade de necessidades que cada curso e que cada professor apresentam. Com base em estudo empírico, ela afirma que, segundo os professores alvo de seu trabalho, seria interessante o acompanhamento do trabalho do jovem professor, dando-lhe uma introdução gradativa, ao assumir a tarefa de ensino como a melhor alternativa na sua formação.

Outro ponto de que tratou por esta autora diz respeito à atividade docente, de certo modo, estar limitada à pesquisa científica. Para Chamlian (2003), a valorização da pesquisa tem-se constituído em fonte de tensão para a maioria dos docentes que depositam, também na atividade de ensino, o objetivo de seu trabalho. Diante dessa realidade, tenta-se desvendar nova alternativa metodológica capaz de inovar a prática docente em sala de aula.

No atual cenário vivenciado pelos discentes dos programas de pós-graduação stricto sensu, nota-se uma preponderância do incentivo à pesquisa, em detrimento da prática do ensino. Fischer (2006) afirma que a formação de pesquisadores teve prioridade até o início da primeira década do novo milênio. Para ela, o fato de haver um trabalho final dissertativo no mestrado e uma tese de doutorado, como requisito formal dos cursos de pós-graduação, teve como consequência o reforço nos currículos de disciplinas e de outras atividades voltadas à formação do pesquisador. Com isso, a autora atenta para o fato de que todos os programas têm disciplinas voltadas à formação do pesquisador. Por outro lado, muito poucos apresentam disciplinas e outras práticas voltadas à formação do professor.

Diante disso, como bem defendem Pimentel, Mota e Kimura (2007), na atualidade observa-se que os mestres e doutores são mais capacitados para o desenvolvimento de pesquisas, mas estão menos preparados para exigências próprias da educação em nível superior. Os autores propõem que, por meio de programas de aperfeiçoamento de ensino, haja a integração de pós-graduandos e graduandos no intuito de promover o intercâmbio de experiências e permitir que o discente de pósgraduação se insira no atual contexto da formação profissional de sua área. Para eles, esta é importante estratégia no processo de ensino-aprendizagem, pois vêm apresentando resultados positivos. Segundo relatos de alunos que passaram por este tipo de programa, ao retornarem às salas de aula e ao convívio com os alunos de graduação, surge nova perspectiva para os mestrandos ou doutorandos, no sentido de confrontar esta experiência em face das mudanças ocorridas e recorrentes no processo educacional.

O estágio pedagógico permite uma primeira aproximação da prática profissional e promove a aquisição de saber, de saber fazer e de saber julgar as consequências das ações didáticas e pedagógicas desenvolvidas no cotidiano profissional (Freire, 2001). Neste sentido, Fischer (2006) discorrem sobre a problemática e deixam claro que a formação de professores não é, nem deve ser, atividade complementar, que acontece a partir do aprendizado do conteúdo; nem apenas pelo só estágio, no qual, segundo as autoras, "alguns programas se desenvolvem simplesmente, colocando alunos de pósgraduação no lugar dos seus orientadores em aulas de graduação" (p. 195). Segundo o enfoque destas pesquisadoras, a simples substituição do professor orientador, sem preparo adequado, não constitui um estágio, mas a execução da docência em caráter precário, além de comprometer a qualidade do ensino de graduação e a formação de mestres na pós-graduação. Elas acreditam que, na maioria dos casos, os programas não se voltam à formação docente porque, por um lado, não sabem exatamente como fazêlo e, por outro, porque não é prioridade valorizada pelas instâncias reguladoras, nem pelos programas.

\section{A Construção da Identidade Docente pelos Pós-Graduandos}

O fato de tornar-se professor, segundo Caires (2006), envolve diferentes aspectos, além da orientação baseada em distintas correntes teóricas. Tais fatores devem ser levados em consideração no processo de formação dos docentes. Para a autora, estas orientações surgem de práticas tecnicistas do 
"aprender a ensinar" (p. 88), ou seja, uma técnica prescritiva, na qual prevalecem os princípios pautados pelo behaviorismo: a prática do ensino é fragmentada e estudada, fração por fração, no sentido de destacar as competências eficazes e, também, de práticas mais reflexivas e humanistas, nas quais a reflexão sob a ação e sobre a ação, bem como a autonomia dos formandos e seu desenvolvimento pessoal, se consideram como centrais neste processo.

Na década de 1980, prevaleceu-se forte investimento na exploração de áreas mais ligadas ao "aprender a ensinar", remetendo às cognições, crenças e processos mentais subjacentes no comportamento dos professores em sala de aula (Caires, 2006, p. 88). No entanto o processo de "tornar-se professor" envolve questões relativas ao modo como é percebida a transição de aluno para professor, às próprias percepções que os alunos têm, como decorrendo do seu primeiro contato com a docência e com o impacto do estágio no seu desenvolvimento vocacional. Estas variáveis integram a dimensão fenomenológica, explorada como possibilidade de alternativas de formação de docentes cada vez mais capazes. Caires (2006) atenta para o fato de o "estágio pedagógico ser aqui entendido como palco de um dos processos mais ricos e decisivos da capacitação e da integração do jovem professor, no mundo da docência e no mundo adulto" (p. 89).

Neste sentido, nota-se que o discente dos cursos de pós-graduação precisa criar uma identidade própria no exercício de suas atividades enquanto professor. Assim, Riolfi e Almaminos (2007) afirmam que um sujeito está em permanente construção de si e de seu trabalho, em processo que pode ser de interminável inovação. Cabe ressaltar que a prática do ensino não deve ser apenas reprodução, mas processo criativo e interativo dos atores envolvidos. O processo de construção de um trabalho deve ser, na medida do possível, condizente com o seu estilo próprio, não se limitando a ser a reprodução. Diante deste fato, o conceito de identificação torna-se fundamental. Nas palavras das autoras supracitadas, pode-se depreender que, em 1921, Freud reconhece explicitamente que "a identificação é conhecida pela psicanálise como a mais remota expressão de um laço emocional com outra pessoa" (Freud, 1921 como citado em Riolfi \& Almaminos, 2007, p. 302).

Estas formas de identificação e aprendizado podem ocorrer das mais diversas maneiras. Mediante a observação, desempenho em sala de aula e pela interação, tanto com orientadores quanto com os alunos e, por meio da ação comunicativa, defendida por Habermas (1999). Neste âmbito, a ação comunicativa é, portanto, não apenas forma de transmissão de informações, mas também aspecto importante da interação social na sociedade, em instituições sociais e na vida diária. Segundo Silva e Davel (2007, p. 54), em contextos de interação social, tal como as "comunidades de prática", a reflexividade é intensificada: promove a aprendizagem e a geração de conhecimento inovador. Ressalta-se que a teoria crítica chama a atenção para a construção social, histórica e política do conhecimento, das pessoas e das relações sociais; todavia vê a resposta em termos de uma forma expandida de raciocínio comunicativo.

Com base nas concepções abordadas por Misoczky e Amantino-de-Andrade (2005), nota-se que Habermas (1999) focou seus trabalhos em termos de crítica evidente da racionalidade instrumental. Para ele, a ciência havia perdido seu caráter crítico, ao pautar-se por esta racionalidade. Neste sentido, Habermas (1999) defende que a emancipação subjetiva gera a possibilidade de simetria entre as relações discursivas e que autonomia e solidariedade passam a ser meras condições para uma ação comunicativa não distorcida.

A partir das concepções da teoria comunicativa e da reflexão e diálogo, pode-se inferir que a figura do supervisor das práticas docentes deve estar associada à idéia de facilitador, criador e dinamizador de contextos da aprendizagem. Além disso, é ele o responsável em proporcionar ambiente de aprendizado contínuo, no qual os professores têm potencialidades para aprenderem, para desenvolver-se e continuarem a sua qualificação, precisando para isso apenas de contextos favoráveis, de apoios e desafios para superar (Alarcão, 2009).

Assim, de acordo com estudo realizado por Rozendo, Casagrande, Schneider, e Pardini (1999), as práticas pedagógicas dos professores universitários refletem a ambiguidade e as contradições de sua profissão e da própria universidade. Além disso, estas práticas pedagógicas revelam que o exercício 
educacional no Brasil continua enraizada na concepção bancária da educação, expressão utilizada por Paulo Freire, para designar a maneira como o ensino assume as informações que são depositadas nas mentes dos alunos, que as recebem sem maiores questionamentos, de forma passiva.

Diante da realidade dos cursos de pós-graduação, Longarez, Nunes, Salge, e Pinheiro (2007) afirmam que o princípio da formação de professores universitários se fundamenta na ideia de que é no diálogo entre a atividade prática docente e sua formação teórica que o professor terá condições de construir uma prática pedagógica crítica; ou, em outros termos, uma práxis crítico-reflexiva. Sob a ótica de Tavares (2005), esse processo de formação e investigação da relação ensino-aprendizagem constitui um dos lugares por onde passam os grandes desafios nas sociedades dos nossos dias. Tudo, porém, depende da preparação e aquisição de novos recursos materiais e humanos, sua classificação e reclassificação, em que os equipamentos físicos e tecnológicos ainda são com certeza determinantes.

Diante do que afirmam Oliveira e Sauerbronn (2007), ao ensino superior de Administração cabe a formação de quadros profissionais que atendam aos novos papéis demandados pela sociedade: mobilidade, elasticidade, criatividade e inovação, tanto nos níveis estratégicos quanto nos operacionais. Esta demanda esbarra no desafio de manter o equilíbrio entre a pesquisa e o ensino da Administração.

Neste sentido, pode-se inferir que, com o crescente número de instituições de ensino superior no mercado brasileiro, surgem preocupações como esta apresentada por Paula e Rodrigues (2006, p. 11):

A tecnologia de fast food é utilizada para padronizar informações e maximizar a quantidade de alunos. Nas 'universidades-lanchonete', professores 'adestrados' apresentam 'receitas de bolo' e 'doutrinas sagradas' dos manuais de gestão.... Nesse contexto, os professores passam a ser entertainers e empreendedores. Como entertainers, eles divertem e estimulam suas platéias com casos, piadas e receitas para o sucesso. Como empreendedores, eles administram seu tempo e atividades sempre com o foco na maximização dos ganhos pessoais.

Observa-se que o distanciamento entre ensino e pesquisa não é interessante nem mesmo necessário. Tal viés prejudica a formação e identidade do corpo docente, além de comprometer a qualidade do ensino oferecido. Como já havia indicado Tragtenberg, em 1979, o foco excessivo em pesquisa pode não refletir necessariamente preocupação com as finalidades sociais do conhecimento, mas mero produtivismo, no qual os artigos servem apenas para medir o sucesso universitário; os congressos são mercados com finalidades comerciais e as revistas são depósitos de textos que não são acessados por praticantes ou grande parte da academia (Oliveira \& Sauerbronn, 2007).

Sob o ponto de vista de Calderón (2004, p. 107), parte das instituições, que ele denomina universidades mercantis, defende o fortalecimento das pesquisas em detrimento da prática do ensino, por considerar que "a ausência da pesquisa impossibilita a reflexão crítica sobre a sociedade". Neste sentido, em diálogo teórico, Siqueira (2005, p. 4) afirma que o conceito utilizado por Calderón (2004) sugere que o objetivo mercantil reduz todas as formas de multidiversidade a uma eficiente "agência de emprego".

No intuito de identificar a percepção dos alunos em relação à prática docente é que se propõe este trabalho. Com o objetivo de relacionar as vantagens e desvantagens advindas da prática e contato direto com as atividades em sala de aula, bem como verificar a importância do estágio docência, como ferramenta metodológica que pode aproximar ensino e pesquisa no ambiente acadêmico.

\section{Metodologia Aplicada ao Estudo}

Perante os objetivos propostos para este estudo, apresentam-se aspectos qualitativos, tendo como método a análise de conteúdo. De acordo com Dellagnelo e Silva (2005), a utilização da análise de conteúdo na pesquisa de administração é tarefa interessante. Tal fato pode ser observado 
especialmente nas pesquisas, cuja abordagem se caracteriza por ser predominantemente qualitativa. Segundo Minayo (2004, p. 74), a análise de conteúdo visa verificar "o que está escrito, falado, mapeado, figurativamente desenhado e/ou simbolicamente explicitado" para a autora, este "sempre será o ponto de partida para a identificação do conteúdo manifesto, seja ele explícito e/ou latente". (p. 74) A análise de conteúdo é considerada uma técnica para o tratamento de dados na qual se tem o objetivo de identificar o que está sendo dito a respeito de determinado tema (Vergara, 2005, p. 15).

É importante ressaltar que a unidade de contexto é a parte mais ampla do conteúdo a ser analisado; porém "é indispensável para a necessária análise e interpretação dos textos a serem descodificados ... e, principalmente, para que se possa estabelecer a necessária diferenciação resultante dos conceitos de significado e sentido" (Puglisi \& Franco, 2005, p. 43). A análise dos dados coletados foi feita em profundidade. Denota-se que existem muitas vantagens em adotar este tipo de método. Entre elas, Bauer e Gaskell (2002) destacam a possibilidade de lidar com alto volume de dados, em que o pesquisador tem autonomia para transitar pela seleção, criação de unidades e categorização de dados brutos.

Para Bauer e Gaskell (2002), o interessante na análise de conteúdo está relacionado à necessidade de se apoiarem em uma técnica de análise de dados de pesquisa qualitativa que alcance alguma credibilidade acadêmica, sem restringir-se aos métodos quantitativos mais clássicos. Estes autores concluem que muitos estudiosos consideram esta técnica equivalente à pesquisa do tipo survey, realizada em documentos. Esta técnica, segundo Dellagnelo e Silva (2005), busca inferir os significados que vão além das mensagens concretas.

Desta forma, em dada situação, analisam-se as características de uma mensagem sem referência às intenções do emissor, ou aos efeitos da mensagem no receptor; em outros casos, busca-se analisar as causas e antecedentes de uma mensagem, de modo a identificar as suas causas e antecedentes, procurando conhecer as suas condições de produção.

Assim, entende-se que o presente trabalho constitui estudo exploratório, de caráter qualitativo, que se desenvolve com base no paradigma interpretativo. Desta forma, pode-se inferir que, sob a perspectiva adotada neste paradigma, toma-se por base a realidade social formada pelas interações realizadas pelos atores envolvidos, uma vez que eles são capazes de interpretar e agir. Epistemologicamente, não buscam leis universais; os métodos utilizados para a investigação e construção do conhecimento acerca do mundo social são pautados pelo uso da interpretação, isto é, entende-se a pesquisa como forma de interação social consistente que ocorre em cenários sociais específicos (Alencar, 2009).

O estudo está embasado na análise de todos os relatórios dos estudantes do Programa de PósGraduação em Administração da Universidade de Federal de Lavras (PPGA/UFLA), matriculados na disciplina de Estágio Docência, no período de agosto de 2008 e junho de 2009, o que corresponde aos segundo e primeiro semestres letivos dos referidos anos. Esta população foi representada por 22 professores-estagiários. De posse dos relatórios destes alunos, foi possível categorizar os dados contidos ditos relatórios. As informações neles contidas são referentes à identificação pessoal do aluno, características gerais referentes à disciplina instrumento do estágio e a questões discursivas, nas quais o discente é livre para discorrer sobre suas percepções e constatações, mediante o estágio por ele desenvolvido.

Os itens constantes nos relatórios em análise compreendem um espaço que serve de base para reflexão sobre alguns dos aspectos mais significativos do estágio, tais como sentimentos positivos e negativos, principais preocupações, aspectos positivos e negativos da supervisão assegurada pelos orientadores e principais ganhos decorrentes do estágio. Tal fato exigiu para este estudo uma abordagem interpretativa, ao analisar as informações coletadas.

Com a finalidade de organizar os itens, foram propostos cinco agrupamentos, no intuito de correlacionar as informações coletadas por meio dos referidos relatórios. Esses dados foram agrupados em categorias denominadas como segue. 
1. Planejamento da disciplina.

2. Contato profissional com a atividade docente.

3. Aproximação e relacionamento com o professor titular da disciplina.

4. Dificuldades enfrentadas no estágio docente.

5. Aprendizagem e habilidade adquirida no desenvolvimento das atividades desempenhadas.

A primeira dimensão, Planejamento da disciplina, abrange dados relacionados ao processo de formulação e junção de materiais que seriam tidos como a base da disciplina e execução da ementa. Já a segunda, Contato profissional com a atividade docente, diz respeito à integração entre estagiário e instituição e, ainda, a percepção do aluno em relação às condições de execução de suas atividades em termos práticos, ou seja, recursos a ele disponibilizados e em que condições suas atividades foram desenvolvidas. A terceira categoria, Aproximação e relacionamento com o professor titular da disciplina, procura evidenciar como aconteceu, de fato, a interação entre professor-mentor e professor-aprendiz. No que se refere à quarta variável, Dificuldades enfrentadas no estágio docente, busca-se fornecer informações referentes ao nível de dificuldades de apoio e acompanhamento, que os estagiários tiveram no desempenho de suas atividades por parte dos supervisores. Por fim, as informações que se referem à quinta categoria, Aprendizado e habilidades adquiridas no desenvolvimento das atividades desempenhadas, foram agrupadas, objetivando elucidar quais as competências, conhecimentos e experiências vivenciados ao longo do estágio contribuíram para a formação desses pós-graduandos, em termos da prática do ensino.

É importante ressaltar, assim como afirma Fonseca (2002), que as conclusões provenientes de uma pesquisa pautada pela análise documental não podem ser apenas um resumo. $O$ pesquisador tem de ter o cuidado de selecionar e analisar cuidadosamente os documentos que pesquisar de modo que se evite comprometer a qualidade da pesquisa com erros resultantes de dados coletados ou processados de forma equivocada.

Além disso, o autor afirma que um ponto que distancia a pesquisa documental da bibliográfica reside no fato de a primeira recorrer a fontes mais diversificadas e dispersas, sem tratamento analítico, enquanto a outra utiliza fontes constituídas por material já elaborado, em geral livros e artigos científicos. Por fim, Alencar (2009) afirma que a coleta de documentos, sejam eles atas, relatórios, estatutos e jornais, entre outros, podem proporcionar uma visão geral do cenário, ou seja, a história, estrutura social, regras e normas, além do contexto no qual o estudo se insere. Por estes motivos é que esta foi considerada a metodologia mais adequada ao estudo proposto.

\section{Resultados e Discussões}

Primeiramente, considera-se que apresentar algumas características deste estudo torna-se relevante, uma vez que embasa o entendimento de colocações que podem surgir ao longo do desenvolvimento deste tópico. Então, serão expostas algumas informações referentes a aspectos que são relacionados aos estudantes do Programa de Pós-graduação em Administração da Universidade de Federal de Lavras (PPGA/UFLA), que se inscreveram na disciplina de Estágio Docência no período do $2^{\circ}$ semestre de 2008 e $1^{\circ}$ semestre de 2009 e entregaram o relatório, que é parte integrante para conclusão da disciplina. Destaca-se que no PPGA/UFLA ingressam, anualmente, 30 alunos para o curso de mestrado e 10 para o curso de doutorado; note-se que eles podem inscrever-se na disciplina Estágio Docência desde o primeiro semestre dos respectivos cursos.

Deste modo, tem-se que do conjunto de relatórios da disciplina Estágio Docência analisados, 22 relatórios no total, 10 são de estudantes do sexo feminino, representando um equilíbrio, se observados na ótica de gênero em relação aos estudantes do sexo masculino (12). Em relação à turma, 15 
estudantes ingressaram no mestrado e 2 estudantes no doutorado no $1^{\circ}$ semestre de 2008; 13 desses alunos já realizaram o estágio no $2^{\circ}$ semestre de 2008, em concomitância com as disciplinas que eles estavam cursando no programa de pós-graduação. Destaca-se que 2 alunos, que ingressaram no mestrado na turma do $1^{\circ}$ semestre de 2009 , realizaram o estágio docência já no $1^{\circ}$ semestre de curso, o que pode influenciar no seu rendimento. Apenas 4 estudantes que cursam a pós-graduação em Administração, no nível de doutorado, compõem o universo deste estudo; todos eles realizaram o estágio docente no $2^{\circ}$ semestre de 2008. Em geral, o professor responsável não repetiu a disponibilidade de disciplinas, ou seja, no período a frequência é de uma orientação de estágio docência por professor, sem que houvesse, também, redundância de disciplinas.

Em relação ao universo analisado, em sua maioria $(77,27 \%)$ os orientadores regulares dos estudantes são os professores responsáveis pelas disciplinas, assumidas por eles para realizar o estágio docência, deixando uma abertura para o que foi constatado por Riolfi e Almaminos (2007), ao afirmarem que, em alguns programas, o estágio docência se desenvolve, simplesmente, colocando alunos de pós-graduação no lugar dos seus orientadores em salas de aula de graduação. Outra constatação que se pode supor é que algumas respostas do relatório podem não refletir o que aconteceu efetivamente durante o estágio docência, já que, implicitamente, os alunos podem não querer prejudicar a relação com seu orientador, omitindo informações no relatório.

Dentre as atividades desenvolvidas pelos alunos no estágio docência, verifica-se que todos ministraram aulas para a graduação e, em alguns casos, assumiram a responsabilidade da disciplina integralmente durante o semestre, sob a tutela do professor responsável. Mais uma vez, relacionandose essa informação com o trabalho de Riolfi e Almaminos (2007), verifica-se, mesmo que em alguns casos, haja a transferência de afazeres de orientadores para orientados. Em Caires (2006), observa-se que o estágio docência apresenta a riqueza justamente pelo contato do futuro professor com a realidade; mas não se pode comprometer essa oportunidade de formação por falta de orientação e acompanhamento.

Realizada a exposição de algumas informações relativas a características do objeto deste estudo e feitas algumas considerações, passa-se a seguir para as análises que objetivam responder ao problema apresentado como norteador deste trabalho.

Considera-se que a Associação Nacional de Pós-graduação em Administração (ANPAD) nasceu junto com os esforços de institucionalizar a pós-graduação no final dos anos 70 , com o objetivo explícito de apoiar a organização do ensino. Nos anos 80 e, especialmente nos anos 90, a pesquisa ocupou o espaço da formação. Os professores tornaram-se pesquisadores; o Conselho Nacional de Desenvolvimento Científico e Tecnológico (CNPq) teve importante papel neste impulso para o fortalecimento da área, enquanto produtora de conhecimento (Fischer, 2006).

Diante deste fato, surge a preocupação, em termos da formação dos professores universitários e de sua capacitação enquanto formadores de novos profissionais. A partir dessa possível banalização do ensino, em relação à pesquisa, é que surge a demanda de avaliar a viabilidade e as contribuições que o desenvolvimento do estágio docência pode trazer para a formação dos pós-graduandos, no sentido de aproximá-los à prática do ensino.

Com a finalidade de detectar quais seriam, de fato, os benefícios provenientes de tal prática, procurou-se identificar os fatores relevantes evidenciados pelos próprios professores-estagiários no desenvolvimento de suas atividades enquanto docentes. Diante da realidade dos programas de pósgraduação que, em grande parte, estão voltados à pesquisa e deixando em segundo plano a atividade de ensino, este trabalho se propõe a elucidar a viabilidade de se promover a junção harmônica entre ensino e pesquisa.

No intuito de facilitar a apresentação destes resultados, eles serão apresentados de acordo com as categorias propostas, nas quais eles foram separados, como mostra a Tabela 1: 
Tabela 1

Avaliação dos Benefícios e Adversidades do Estágio Docência Estruturados por Categoria

\begin{tabular}{|c|c|c|c|c|}
\hline Categoria 1 & Categoria 2 & Categoria 3 & Categoria 4 & Categoria 5 \\
\hline $\begin{array}{l}\text { Planejamento da } \\
\text { disciplina }\end{array}$ & $\begin{array}{c}\text { Contato profissional } \\
\text { com a atividade } \\
\text { docente }\end{array}$ & $\begin{array}{c}\text { Aproximação e } \\
\text { relacionamento com o } \\
\text { professor titular da } \\
\text { disciplina }\end{array}$ & $\begin{array}{c}\text { Dificuldades } \\
\text { enfrentadas no estágio } \\
\text { docente }\end{array}$ & $\begin{array}{c}\text { Aprendizagem e } \\
\text { habilidade adquirida no } \\
\text { desenvolvimento das } \\
\text { atividades } \\
\text { desempenhadas }\end{array}$ \\
\hline $\begin{array}{l}\text { - Inclusão de um } \\
\text { planejamento das } \\
\text { atividades que serão } \\
\text { desenvolvidas; } \\
\text { · Maior tempo para } \\
\text { execução do estágio; } \\
\text { - O estágio e o curso de } \\
\text { aperfeiçoamento } \\
\text { deveriam ser uma } \\
\text { exigência; } \\
\text { - Promover palestras e } \\
\text { aulas práticas para } \\
\text { complementar as } \\
\text { atividades em sala de } \\
\text { aula; } \\
\text { Sistematização das } \\
\text { atividades; } \\
\text { Possibilidade de } \\
\text { realizar estágio também } \\
\text { em cursos de graduação } \\
\text { a distância; } \\
\text { - Programa de docência } \\
\text { voluntária como } \\
\text { alternativa ao estágio; } \\
\text { Dificuldade em } \\
\text { conciliar estágio e } \\
\text { disciplinas obrigatórias } \\
\text { do mestrado; } \\
\text { e falta de prática } \\
\text { comprometeram } \\
\text { ministradas. }\end{array}$ & 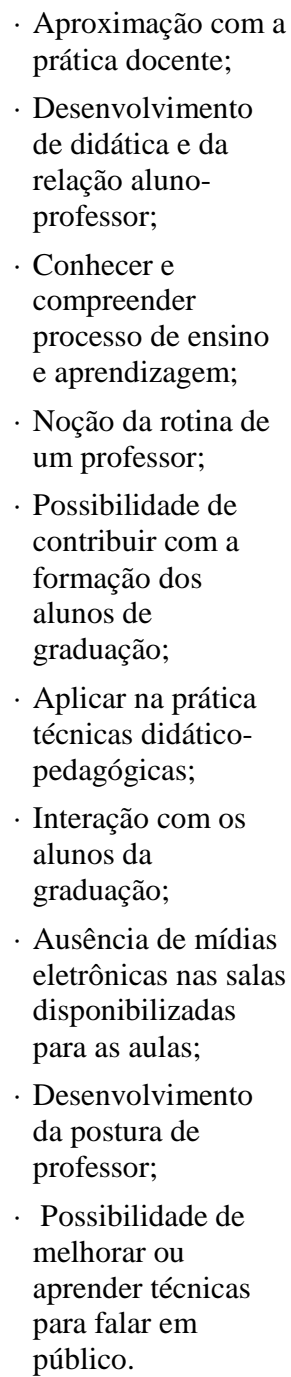 & $\begin{array}{l}\text { - Avaliação positiva } \\
\text { da viabilidade e } \\
\text { facilidade de } \\
\text { interação de } \\
\text { professor e } \\
\text { estagiário, sendo o } \\
\text { conceito dado de } \\
\text { "Muito Bom" a } \\
\text { "Ótimo"; } \\
\text { · Interação na } \\
\text { preparação de todo } \\
\text { o processo referente } \\
\text { à disciplina; } \\
\text { - Auxílio do professor } \\
\text { e discussões para a } \\
\text { aplicação da melhor } \\
\text { metodologia de } \\
\text { ensino; } \\
\text { - Troca de } \\
\text { experiências, por } \\
\text { meio de reuniões; } \\
\text { - Criação de elos de } \\
\text { confiança; } \\
\text { - Pouco contato e } \\
\text { falta de } \\
\text { acompanhamento do } \\
\text { professor titular. }\end{array}$ & $\begin{array}{l}\text { - Informações } \\
\text { desencontradas, } \\
\text { obscuras e } \\
\text { superficiais; } \\
\text { - Atraso na } \\
\text { designação da } \\
\text { disciplina; } \\
\text { - Carência de um } \\
\text { acompanhamento } \\
\text { mais próximo por } \\
\text { parte de um } \\
\text { professor supervisor; } \\
\text { Falta feedback e } \\
\text { maior interação com } \\
\text { o professor } \\
\text { responsável; } \\
\text { Crítica ao fato de se } \\
\text { assumir } \\
\text { integralmente uma } \\
\text { disciplina; } \\
\text { Falta um programa } \\
\text { formal das } \\
\text { atividades } \\
\text { desenvolvidas. }\end{array}$ & $\begin{array}{l}\text { - Aprimoramento da } \\
\text { prática docente; } \\
\text {. Desenvolvimento de } \\
\text { técnicas didáticas; } \\
\text { - Aprendizado, por meio } \\
\text { de atuação e } \\
\text { observação, da postura } \\
\text { diante do alunado; } \\
\text { Contato estreito com o } \\
\text { processo de } \\
\text { aprendizado, tanto } \\
\text { como professor quanto } \\
\text { como aluno; } \\
\text { - Confronto do estágio e } \\
\text { curso de } \\
\text { aperfeiçoamento no } \\
\text { intuito de aliar teoria e } \\
\text { prática; } \\
\text { - Interação com alunos } \\
\text { da graduação; } \\
\text { - Aperfeiçoamento, por } \\
\text { meio da prática, de } \\
\text { técnicas de oratória; } \\
\text { - Experiência de tomada } \\
\text { de decisão com bases } \\
\text { pedagógicas; } \\
\text { concentração se } \\
\text { configura em grande e } \\
\text { enriquecedor desafio. }\end{array}$ \\
\hline
\end{tabular}

Nota. Fonte: Dados da pesquisa.

Por meio da análise de conteúdo dos relatórios e da pesquisa bibliográfica, Caires (2006), Fischer (2006), Freire (2001), Pimentel et al. (2007), Riolfi e Almaminos (2007), por exemplo, percebe-se que o estágio docência traz novos desafios aos alunos de pós-graduação. Muitos deles acreditam que a maior contribuição advinda da prática e vivência do ensino em sala de aula diz respeito ao aprimoramento da prática docente, bem como à possibilidade de aplicar as técnicas didático-pedagógicas aprendidas nos programas de aperfeiçoamento oferecidos pelas instituições de ensino superior (IES). Para os mestrandos e doutorandos que participaram deste estudo, o desenvolvimento da didática e o contato estreito com a relação aluno-professor foi ingrediente fundamental para o desenvolvimento de habilidades que serão ainda mais aprimoradas no exercício da profissão de educador. 
Entre os vários pontos ressaltados pelos professores-estagiários, alguns merecem destaque, seja pela sua notória importância, seja até mesmo pela sua recorrente incidência. Assim, pode-se depreender que os fatores relacionados ao contato prático com o ensino e interação com os alunos foi um fator bastante valorizado pelos discentes que desenvolveram o estágio. Além disso, deixaram clara a sua satisfação em conhecer o processo de aprendizagem e lidar diretamente com ele e sua participação fundamental na relação aluno-professor. Para alguns deles, essa foi a primeira experiência na qual ele assumia o papel de professor na referida relação. Apesar de representar um desafio composto de diversos obstáculos, grande parte dos estagiários revelou quão positiva fora a oportunidade deste primeiro contato com a atividade docente de modo profissional. Apesar de apresentarem muito mais pontos positivos para a execução da atividade, os alunos também puderam identificar alguns pontos negativos no que tange à primeira categoria de dados proposta: Planejamento da Disciplina.

Nesta categoria, os pós-graduandos, no $2^{\circ}$ semestre de 2008 , ressaltaram que faltava um planejamento de execução das atividades, que o estágio pode ser comprometido pela dificuldade de conciliá-lo com as disciplinas obrigatórias do programa de pós-graduação e, ainda, propuseram que seja criada uma sistematização das atividades, de modo que as atividades a serem desempenhadas pelo professor-estagiário já estejam elencadas no início do desenvolvimento do estágio. Fato que parece ter sido percebido pelos responsáveis pela disciplina Estágio Docência: já no $1^{\circ}$ semestre de 2009, por meio dos relatórios, observou-se que algumas das reclamações já tinham sido amenizadas.

Aliás, surgiram sugestões no sentido de que o estágio e o curso de aperfeiçoamento oferecido pela universidade, que faz parte do conteúdo do estágio docência, deveriam ser uma exigência dos programas, uma vez que eles são de extrema relevância para a formação de mestres e doutores capacitados para a atividade de docência. Muitos alunos apontaram a pequena oferta de disciplinas, mediante a demanda de pós-graduandos interessados em realizar o estágio. Em uma tentativa de resolver tal impasse, propõe-se que, além do Programa de Docência Voluntária, também pudessem contar como estágio docência as práticas de ensino realizadas nos cursos de graduação a distancia, oferecidos pela própria UFLA, uma vez que esse formato de ensino tem crescido substancialmente.

Enfim, verifica-se que alguns alunos tiveram seu estágio comprometido pelo pouco ou nenhum acompanhamento do desenvolvimento do estágio por parte do professor responsável. Conforme alertaram Riolfi e Almaminos (2007), como já citado anteriormente, a simples substituição do professor orientador, sem preparo adequado, não constitui um estágio, mas a execução da docência em caráter precário. Alguns alunos afirmaram que, pela falta de experiência e ausência de uma orientação reflexiva, o acúmulo de atividades, aliado a essas carências, contribuiu para a queda da qualidade das aulas ministradas.

$\mathrm{Na}$ segunda categoria foram agrupados os dados referentes ao Contato profissional como atividade docente. Os professores-estagiários avaliaram de maneira bastante positiva este contato como importante atividade relacionada à formação deles enquanto professores. Grande parte dos envolvidos discorreu sobre os benefícios provenientes da aproximação com a prática docente, afirmaram ter tido a oportunidade de aprender empiricamente o processo de ensino e aprendizagem, bem como o desenvolvimento de didática em sala de aula na relação aluno-professor. Uma das maiores contribuições ressaltadas por eles reside na possibilidade que os estagiários têm de contribuir para a formação dos alunos da graduação, em clara demonstração da construção social mediante a reflexividade e o diálogo. Como pontos de defasagem neste processo, a ausência de mídias eletrônicas nas salas de aula constituiu um ponto que dificultou um pouco as atividades, porém nada que comprometesse a qualidade das atividades desenvolvidas. Muitos afirmaram que absorveram algumas posturas que julgaram interessante adotar no exercício do ensino. Neste sentido, pode-se inferir que o contato profissional com a docência é fundamental para o início de uma carreira acadêmica e, até mesmo, para a definição de uma carreira profissional e equilíbrio da formação de professores e pesquisadores na área de Administração, conforme observaram Caires (2006) e Oliveira e Sauerbronn (2007), já que, em muitos casos, os cursos de pós-graduação stricto sensu se concentram apenas na pesquisa, pela preocupação com o trabalho final do curso, dissertação ou tese, e ainda por causa das exigências das instituições de fomento quanto à publicação e desenvolvimento de pesquisas. 
Considerando a terceira categoria, Aproximação e relacionamento com o professor titular da disciplina, observa-se que houve alguns pontos de divergência entre os alunos participantes deste estudo. A turma se mostrou divergente, ao expor como foi o processo de interação e integração com o professor titular da disciplina: em uma questão que solicitava o posicionamento de forma clara, eles ressaltaram apenas benefícios e pontos positivos quanto a essa relação de professor titular e professor estagiário que, em sua maioria, é também a relação orientador e orientado regular no curso, sejam eles de mestrado ou doutorado. No entanto, em outra questão mais abrangente, que permitia que eles relatassem as dificuldades no estágio docência, surgiram queixas a respeito dessa relação que se aborda nessa categoria.

Dessa forma, o entusiasmo e pensar positivo de uma questão contrastaram com a identificação de possíveis problemas de acompanhamento, supervisão e auxílio: em alguns casos, os professores titulares deixaram por conta dos professores-estágiários toda a carga da disciplina ministrada na graduação, conforme exposto por alguns dos estudantes nos relatórios. Isso acarretou a descontinuidade no processo de aprendizagem dos estagiários, porquanto, segundo Longarez et al. (2007), o princípio da formação de professores universitário fundamenta-se na idéia de que é no diálogo entre a atividade prática docente e sua formação teórica, construindo uma prática pedagógica crítica ou, em outros termos, uma práxis crítico-reflexiva. Isto não ocorreu, quando o professor titular não acompanhou os estagiários e não houve reflexividade e feedbacks. Ressalta-se que, em alguns casos, não houve descrição detalhada da resposta por parte dos alunos, apenas conceituando, nas quais a maioria entendeu que relação com o professor titular foi Ótima, em primeiro momento, mas em alguns casos surgiu a divergência citada acima.

A quarta dimensão avaliada foi o aspecto de Dificuldades enfrentadas no estágio docente. Ela complementa a terceira categoria. Nesta dimensão, agrupou-se o que os alunos deixaram como suas considerações acerca de possíveis mudanças para o desenvolvimento do estágio docência para as turmas seguintes. A partir das considerações feitas por eles, observa-se que as informações no início e, também, durante o desenvolvimento do estágio, não foram transmitidas de maneira clara e objetiva. Além disso, alguns atentaram para a superficialidade com que algumas questões foram tratadas pelos professores titulares. Neste âmbito, houve atraso na designação de disciplinas; muitos alunos, possivelmente aqueles que assumiram as disciplinas em sua totalidade, sentiram certa carência de acompanhamento mais próximo por parte de um professor orientador. Além disso, reclamaram a ausência de feedback e interação do professor titular com o professor-estagiário, bem como de um programa formal no qual estejam predeterminadas quais seriam as atividades desenvolvidas e o cronograma de execução. Destaca-se que as sugestões e críticas foram mais acentuadas pelos estudantes que fizeram o estágio no $2^{\circ}$ semestre de 2008, sendo possível perceber nas exposições dos que realizaram, no $1^{\circ}$ semestre de 2009 , uma descrição mais positiva quanto à organização da disciplina. No entanto algumas reclamações continuaram, principalmente quanto à conciliação das atividades regulares do curso de mestrado e o estágio docência, já que em 1\%/2009 foi quando se observou que dos 5 estagiários, todos eles mestrandos, 2 tinham acabado de ingressar no curso. Aparecem, em alguns relatórios, sugestões para que se evite tal acontecimento; neste caso parte dos orientadores regulares dos mestrandos certo direcionamento, no intuito de evitar um desgaste dos alunos e para melhorar a qualidade do ensino transmitido na graduação.

O último agrupamento apresentado se refere à Aprendizagem e habilidade adquirida no desenvolvimento das atividades desempenhadas. Nesta categoria se estruturou o que os alunos elucidaram como os benefícios e as vantagens de desenvolver o estágio docência, em termos de uma metodologia de ensino que melhor os capacite à prática do ensino. Assim, cabe ressaltar que foram muitos os pontos positivos por eles enumerados, tais como:

\section{Aprimoramento da prática docente;}

Desenvolvimento de técnicas didáticas;

Aprendizado, por meio de atuação e observação, da postura diante do alunado; 
- Contato estreito com o processo de aprendizado, tanto como professor quanto como aluno;

- Confronto do estágio e curso de aperfeiçoamento no intuito de aliar teoria e prática;

· Interação com alunos da graduação;

- Aperfeiçoamento, por meio da prática, de técnicas de oratória, entenda-se domínio da língua;

- Experiência de tomada de decisão com bases pedagógicas; e,

- Lecionar uma disciplina que não pertencia à área de concentração de seu projeto de mestrado ou doutorado, como aconteceu em determinados casos, foi apontado como grande e enriquecedor desafio.

Verifica-se, então, que os métodos de observação e interação com os profissionais mais experientes trouxeram ganhos de fato àqueles que construíram o aprendizado de maneira reflexiva, quando houve a interação dos professores titulares com os professores-estagiários. Além disso, a socialização no ambiente universitário e o contato com a profissão docente foram descritos como excelente alternativa para os primeiros contatos e consequente aprimoramento da prática docente.

Enfim, pode-se inferir que a experiência direta e a reflexão sobre o ato de ensino ou, ainda, o fato de assumir novas responsabilidades configuram-se como oportunidade de associar as unidades de teoria e prática, conforme já observado por Caires (2006), Fischer (2006), Longarez et al. (2007), Oliveira e Sauerbronn (2007). O relatório da disciplina Estágio Docência apresenta efetividade para mudanças e melhorias na estrutura e direcionamento da disciplina. Porém há que levar em conta a fragilidade que esta ferramenta de análise apresenta. A simples análise dos relatórios produzidos pelos alunos de estágio docência não têm consistência suficiente para conclusões mais aprofundadas. Isto pode ser observado, em especial, nos momentos em que o relatório traz questões referentes ao relacionamento que o professor-estagiário teve com o professor responsável pela disciplina. Neste momento, ficou evidente que as respostas não foram fiéis à realidade. Isto aconteceu porque boa parte dos alunos assumiu as disciplinas cujos responsáveis eram seus orientadores na graduação. Tal fato intimidou e constrangeu alguns alunos em seus relatos finais; porém, nos demais quesitos, este relatório contribuiu significativamente para estas constatações preliminares.

\section{Considerações Finais}

Por meio dos resultados e análises deste trabalho, entende-se que o estágio docência é uma possibilidade de aliar pesquisa e ensino, tornando-se estratégia bastante interessante no processo de formação de novos docentes. Os alunos que participaram desta experiência expuseram opiniões e sugestões, para que esta alternativa fosse apontada como básica e de relevância para os demais alunos do Programa de Pós-graduação em Administração da Universidade Federal de Lavras (PPGA/UFLA). Pelo fato de os cursos de pós-graduação stricto sensu serem a principal via de formação de professores universitários, torna-se proeminente a prática do ensino em conformidade e harmonia com a pesquisa, e não um sobrepujando a outra e vice-versa.

Considera-se que, para maiores contribuições provenientes da prática reflexiva do ensino sejam detectadas, faz-se necessária a adoção de critérios claros e objetivos dos métodos avaliativos do estágio docência e mais retorno aos estagiários, e que o professor titular não se isente de suas responsabilidades, ao entregar a disciplina em sua totalidade ao professor aprendiz. Além disso, um planejamento das atividades e objetivos das disciplinas também poderia ser uma forma de potenciar os ganhos provenientes desta experiência.

Outro fator que merece destaque é que, em contextos de interação social, como no caso da sala de aula, práticas mais reflexivas pautadas pelo diálogo podem trazer vantagens ao processo de 
aprendizagem, tanto para o professor-estagiário quanto para os alunos da graduação envolvidos neste processo. A reflexão sob a ação e sobre a ação, assim como a autonomia dos pós-graduandos promovem seu desenvolvimento pessoal. Logo, a reflexividade é intensificada, o que promovem o aprendizado e a geração do conhecimento.

Entende-se que, para que haja maior interação e troca de informações, deveria haver, periodicamente, reuniões entre estagiários, professores titulares das disciplinas e, até, os orientadores. Estes poderiam contribuir para o estreitamento de laços e consequente aumento da identificação entre as partes. Além disso, deveriam ocorrer avaliações do desempenho dos professores-estagiários, para que eles pudessem ter exata noção do seu trabalho e de possíveis mudanças de postura, quando necessárias.

Em resposta à ausência de supervisão, ressaltada por alguns alunos, segundo Alarcão (2009), no estágio docência deve haver três tipos de supervisão: supervisão hierárquica, em que o professor titular deve ser personificado nesta posição; a alterissupervisão, que deve ser comprometida e os participantes devem colaborar uns com os outros, em prol do desenvolvimento e melhoria do próprio ensino; por fim, a autosupervisão, cujas atribuições são, como o próprio nome diz, o ato reflexivo de supervisionar as próprias atividades e consequências de seus atos.

Assim, de acordo com as proposições de Longarez et al. (2007), o que deve ocorrer no desenvolvimento das atividades do estágio docência é trabalho coletivo. Dessa forma, o desafio é desenvolver este trabalho durante todo o processo de organização do ensino: na concepção, no planejamento, na execução e na avaliação. Portanto compreende-se que o processo de formação de professores universitários demanda integração de teoria e prática, concomitância com a interação dos envolvidos no processo, em que o envolvimento com o estágio docência é uma forma eficaz e efetiva de promover a prática do ensino nas universidades.

Para futuros trabalhos, sugere-se que se aprofundem mais as questões que ainda são barreiras para a disciplina de Estágio Docência nos programas de pós-graduação stricto sensu na área de Administração, de modo especial em relação ao modo como o trabalho tem sido conduzido pelos programas. Além disso, haja estudos que gerem contribuições mais generalistas, pois este estudo não apresenta essa característica, que compare a satisfação e aptidão dos estudantes junto ao estágio docente. Cabe ressaltar, ainda, que este não visa ser um trabalho que esgote o tema; ele apresenta apenas uma luz sobre questões que permeiam a prática da docência e as ferramentas utilizadas pelos programas de pós-graduação, no que tange à formação de professores universitários.

\section{Agradecimentos}

Os autores agradecem a CAPES, pelo apoio financeiro.

\section{Nota}

${ }^{1}$ Este trabalho foi apresentado no II Encontro de Ensino e Pesquisa em Administração e Contabilidade.

\section{Referências}

Alarcão, I. (2009). Formação e supervisão de professores: uma nova abrangência. Revista de Ciências da Educação, (8), 119-128. 
Alencar, E. (2009). Metodologia de pesquisa [Material didático]. Universidade Federal de Lavras, Lavras, MG.

Bauer, M. W., \& Gaskell, G. (2002). Pesquisa qualitativa com texto, imagem e som: um manual prático (4a ed.). Petrópolis: Vozes.

Caires, S. (2006). Vivências e percepções do estágio pedagógico: contributos para a compreensão da vertente fenomenológica do "tornar-se professor". Análise Psicológica, 24(1), 87-98.

Calderón, A. I. (2004). Repensando o papel da universidade. Revista de Administração de Empresas, 44(2), 104-108. doi: 10.1590/S0034-75902004000200009

Chamlian, H. C. (2003). Docência na universidade: professores inovadores na USP. Cadernos de Pesquisa, (118), 41-64. doi: 10.1590/S0100-15742003000100003

Coordenação de Aperfeiçoamento do Pessoal de Nível Superior. (1999). Circular $n^{\circ} 28$, de $1^{\circ}$ de setembro de 1999. Estabelece requisitos para concessão de bolsas. Diário Oficial [da] República Federativa do Brasil, Brasília, 12 novembro, 1999. Recuperado em 28 agosto, 2009, de http://www.jusbrasil.com.br/diarios/1468634/dou-secao-3-12-11-1999-pg-61

Dellagnelo, E. H. L., \& Silva, R. C. (2005). Análise de conteúdo e sua aplicação em pesquisa na administração. In M. M. F. Vieira \& D. M. Zouain (Orgs.), Pesquisa qualitativa em administração: teoria e prática (pp. 97-118). Rio de Janeiro: FGV.

Fischer, T. (2006). Uma luz sobre as práticas docentes na pós-graduação: a pesquisa sobre ensino e aprendizagem em administração. Revista de Administração Contemporânea, 10(4), 193-197. doi: $10.1590 / \mathrm{S} 1415-65552006000400010$

Fonseca, J. J. S. da (2002). Metodologia da pesquisa científica [Material didático]. Universidade Federal do Ceará, Fortaleza, CE.

Freire, A. M. (2001). Concepções orientadoras do processo de aprendizagem do ensino nos estágios pedagógicos. Faculdade de Psicologia e de Ciências da Educação, Universidade de Lisboa, Lisboa, Portugal. Recuperado em 30 julho, 2009, de http://www.educ.fc.ul.pt/recentes/mpfip/pdfs/afreire.pdf

Habermas, J. (1999). Teoria da ação comunicativa I. Madrid: Taurus.

Longarez, A. M., Nunes, A. T. T., Salge, E. H. C. N., \& Pinheiro, N. C. A. (2007). A unidade teoria e prática no contexto da formação de professores. Revista Profissão Docente, 7(1), 15-08. $\begin{array}{lllll}\text { Recuperado em } & 30 & \text { julho, } & 2009,\end{array}$ http://www.uniube.br/propep/mestrado/revista/vol07/15/artigos/Artigo_15_010.pdf

Minayo, M. C. (2004). O desafio do conhecimento: pesquisa qualitativa em saúde. São Paulo: HUCITEC.

Misoczky, M. C., \& Amantino-De-Andrade, J. (2005). Uma crítica à crítica domesticada nos estudos organizacionais. Revista de Administração Contemporânea, 9(1), 215-233. doi: 10.1590/S141565552005000100010

Oliveira, F. B. de, \& Saurbronn, F. F. (2007). Trajetória, desafios e tendências no ensino superior de administração [Edição Especial]. Revista de Administração Pública, 41, 149-170. doi: 10.1590/S0034-76122007000700009

Paula, A. P. P., \& Rodrigues, M. A. (2006). Pedagogia crítica no ensino da administração: desafios e possibilidades [Edição Especial]. Revista de Administração de Empresas, 46, 10-22. 
Pimentel, V., Mota, D. D. C. F., \& Kimura, M. (2007). Reflexões sobre o preparo para a docência na pós-graduação em enfermagem. Revista da Escola de Enfermagem da USP, 41(1), 161-164. doi: 10.1590/S0080-62342007000100022

Puglisi, M. L., \& Franco, B. (2005). Análise de conteúdo (2a ed.). Brasília: Líber Livro.

Riolfi, C. R., \& Almaminos, C. (2007). Os pontos de virada na formação do professor universitário: um estudo sobre o mecanismo da identificação. Educação e Pesquisa, 33(2), 297-310. doi: $10.1590 /$ S1517-97022007000200008

Rozendo, C. A., Casagrande, L. D. R., Schneider, J. F., \& Pardini, L. C. (1999, abril). Uma análise das práticas docentes de professores universitários da área de saúde. Revista Latino Americana de Enfermagem, 7(2), 15-23. doi: 10.1590/S0104-11691999000200003

Silva, J. C. S., \& Davel, E. (2007). Da ação à colaboração reflexivas em comunidades de prática. Revista de Administração de Empresas, 47(3), 53-65. doi: 10.1590/S0034-75902007000300005

Siqueira, M. M. de. (2005). O ensino superior e a universidade. RAE eletrônica, 4(1). Recuperado em 30 julho, 2009, de http://www.scielo.br/pdf/raeel/v4n1/v4n1a15.pdf

Tavares, J. (2005, abril). Aprender e ensinar como uma construção pessoal e social do conhecimento. Recuperado em 30 julho, 2009, de http://www2.dce.ua.pt/LEIES/daes_pt_artigo_brasil.pdf

Tragtenberg, M. (1979). A delinqüência acadêmica: o poder sem saber e o saber sem poder. São Paulo: Rumo.

Vergara, S. C. (2005). Métodos de pesquisa na administração. São Paulo: Atlas. 